\title{
Vitamin C Supplementation and Common Cold Symptoms: Problems with Inaccurate Reviews
}

\author{
HARRI HEMILÄ, PHD \\ From the Department of Public Health, University of Helsinki, Finland \\ Date accepted: 17 May 1996
}

\begin{abstract}
In 1971, Linus Pauling carried out a meta-analysis of four placebo-controlled trials and concluded that it was highly unlikely that the decrease in the "integrated morbidity of the common cold" in vitamin C groups was caused by chance alone $(P<0.00003)$. Studies carried out since then have consistently found that vitamin $C(\geq 1 \mathrm{~g} / \mathrm{d})$ alleviates common cold symptoms, indicating that the vitamin does indeed have physiologic effects on colds. However, widespread conviction that the vitamin has no proven effects on the common cold still remains. Three of the most influential reviews drawing this conclusion are considered in the present article. Two of them are cited in the current edition of the RDA nutritional recommendations as evidence that vitamin $\mathrm{C}$ is ineffective against colds. In this article, these three reviews are shown to contain serious inaccuracies and shortcomings, making them unreliable sources on the topic. The second purpose is to suggest possible conceptual reasons for the persistent resistance to the notion that vitamin $\mathrm{C}$ might have effects on colds. Although placebo-controlled trials have shown that vitamin $C$ does alleviate common cold symptoms, important questions still remain. @Elsevier Science Inc. 1996 Nutrition 1996; 12:804-809
\end{abstract}

Key words: ascorbic acid, common cold, upper respiratory infections, rhinovirus, clinical trials, therapy

\section{INTRODUCTION}

In the early 1970s, Linus Pauling ${ }^{1,2}$ suggested that vitamin C $(\geq 1 \mathrm{~g} / \mathrm{d}$ ) may substantially decrease the incidence and severity of common cold episodes. Pauling did not carry out his own experimental work on the topic but derived his conclusions from earlier studies. Since Pauling's analyses a large number of trials have been carried out to examine whether the vitamin really does have an effect on colds. ${ }^{3,4}$ These reports have shown that vitamin C supplementation has no marked effect on common cold incidence in the general population. However, the symptoms of the common cold have consistently been alleviated. Table I shows the results of all placebo-controlled trials in which $\geq 2 \mathrm{~g} / \mathrm{d}$ of vitamin $\mathrm{C}$ was regularly administered to the subjects. All eight studies found a statistically significant benefit in at least one of the outcome parameters. The combined $P$ value is extremely small for the five studies published up to 1975, indicating that in 1975 or earlier an unequivocal conclusion could have been drawn that vitamin $\mathrm{C}$ alleviates the symptoms of the common cold. Six of the eight studies found that the duration or severity of colds was decreased by more than $20 \%$ in the vitamin group, suggesting that the effect may be of practical importance. Nevertheless, there has been great quantitative variation in the results, hampering the evaluation of the clinical significance of vitamin $\mathrm{C}$ in treating colds (Table $\mathrm{I}^{3,4}$ ).

Although placebo-controlled trials have consistently found benefit from vitamin $\mathrm{C}$ on common cold symptoms, a widespread belief that the vitamin has no real effects on the common cold still remains. ${ }^{20-22}$ In this paper we shall briefly analyze three of the most influential reviews which have concluded that vitamin $\mathrm{C}$ has no proven effects on the common cold, ${ }^{23-25}$ in order to expose their major shortcomings. The second purpose of the present work is to suggest possible conceptual reasons why there has been such persistent resistance to the notion that vitamin $\mathrm{C}$ has effects on common cold symptoms.

\section{ANALYSIS OF THE THREE MAJOR REVIEWS}

Chalmers' 1975 Review

In 1975 Thomas Chalmers analyzed the results of seven placebo-controlled vitamin C-common cold studies which he

This work was supported by the Academy of Finland.

Correspondence to: Harri Hemilä, PhD, Department of Public Health, P.O. Box 41, University of Helsinki, Helsinki, FIN-00014, Finland.

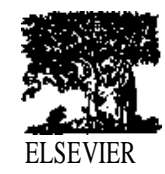


TABLE I.

\section{VITAMIN C SUPPLEMENTATION AND COMMON COLD SYMPTOMS}

\begin{tabular}{|c|c|c|c|c|c|c|}
\hline Study (Ref.) & $\begin{array}{l}\text { Subjects, } \\
\text { Country }\end{array}$ & $\begin{array}{l}\text { Dose } \\
(\mathrm{g} / \mathrm{d})\end{array}$ & $\begin{array}{c}\text { No. of episodes } \\
\text { in vitamin C group }\end{array}$ & $\begin{array}{l}\text { Effect on duration } \\
\quad \text { or severity }\end{array}$ & $P$ (one-tail) & $-2 \times \ln (P)$ \\
\hline \multicolumn{7}{|l|}{ Studies up to 1975} \\
\hline Anderson et al. $1972(5,6)$ & Adults, Canada & $1+3^{b}$ & 561 & $\begin{array}{l}-21^{\mathrm{c}} \\
-5\end{array}$ & 0.008 & $9.66^{*}$ \\
\hline Elliott 1973 (7) & $\begin{array}{l}\text { Military recruits, } \\
\text { USA }\end{array}$ & 2 & $37^{\mathrm{d}}$ & $-72^{\mathrm{e}}$ & 0.016 & $8.27 *$ \\
\hline Schwartz et al. 1973 (8) & Adults, USA & 3 & $11^{\mathrm{f}}$ & $-30^{\mathrm{g}}$ & 0.005 & $10.60 *$ \\
\hline Coulehan et al. 1974 (9) & $\begin{array}{l}\text { School children, } \\
\text { USA }\end{array}$ & 2 & 16 & -29 & $0.006^{\mathrm{h}}$ & $10.23 *$ \\
\hline Karlowski et al. $1975(10,11)$ & Adults, USA & $3+3^{b}$ & 76 & -17 & 0.025 & $7.38^{*}$ \\
\hline \multicolumn{7}{|l|}{ Studies after 1975} \\
\hline Pitt \& Costrini 1979 (12) & $\begin{array}{l}\text { Military recruits, } \\
\text { USA }\end{array}$ & 2 & 600 & $\begin{array}{l}-5^{\mathrm{i}} \\
-3\end{array}$ & 0.012 & 8.85 \\
\hline Bancalari et al. 1984 (13) & $\begin{array}{l}\text { School children, } \\
\text { Chile }\end{array}$ & 2 & 38 & -24 & 0.041 & 6.39 \\
\hline Mink et al. 1988 (14) & Adults, USA & 2 & $4^{\mathrm{f}}$ & $-50^{\mathrm{i}}$ & 0.023 & 7.55 \\
\hline
\end{tabular}

* Five studies up to $1975: \chi^{2}(10 \mathrm{df})=46.1$ combined $P$ (two-tail $)=0.000002$.

All eight studies: $\chi^{2}(16 \mathrm{df})=68.9$ combined $P$ (two-tail $)=0.00000002$.

NOTES: Studies in which $\geq 2 \mathrm{~g} / \mathrm{d}$ of vitamin $\mathrm{C}$ was regularly administered were selected. The eight studies in the table were double-blind placebo-controlled studies and five were randomized. ${ }^{5,7,10,12,13}$ For short-term studies, supplementation was initiated before the symptoms started and continued after the symptoms ended. Anderson et al.'s ${ }^{5} 1972$ study was included in the table as the dose during the episodes was 4 g/d although the regular dose was only $1 \mathrm{~g} / \mathrm{d}$. Anderson's 1974 study was excluded since there is bias in the distribution of subjects in the study groups. ${ }^{15,16}$ For the studies by Anderson et al. ${ }^{5}$ and Pitt and Costrini, ${ }^{12}$ the days indoors and severity of symptoms, respectively, were selected as outcomes in the calculations. For a more comprehensive list of the original data see Table 1 in Ref. 3 . The weighted mean was calculated using the number of episodes in the vitamin $\mathrm{C}$ group as the weight. The $P$ values were recalculated when appropriate data were available. The combined $P$ value was calculated by the Fisher method. ${ }^{17-19}$

${ }^{\mathrm{a}}$ The outcome is the duration of cold symptoms except when otherwise indicated. ${ }^{\mathrm{b}}$ At the onset of a cold episode an additional 3 g/d was given for $3-5 \mathrm{~d}$. ${ }^{\mathrm{C}}$ Days confined to house per episode. ${ }^{\mathrm{d}}$ The number of subjects; the number of episodes is not given in the report. ${ }^{\mathrm{e}} \mathrm{Days}$ of morbidity for sore throats. ${ }^{\mathrm{f}}$ Induced rhinovirus infection. ${ }^{\mathrm{g}}$ Total illness score at the 4 th $\mathrm{d}$ after challenge. ${ }^{\mathrm{h}} P$ value for comparing the number of sickness days between the groups. ${ }^{i}$ Severity of symptoms.

considered technically acceptable. ${ }^{23}$ He calculated that the episodes were $0.11 \pm 0.24$ (SE) days shorter in the vitamin $\mathrm{C}$ groups compared to the placebo groups. Even if real, a 0.11 day decrease in the duration of a cold episode is without any clinical significance. Moreover, the great variation in the results, as indicated by the standard error, suggests that there probably was no real effect at all.

Recently, Chalmers' review was shown to contain serious errors. ${ }^{16}$ For example, in some cases the data presented were inconsistent with the originally published results. Neither did Chalmers consider the amount of vitamin $\mathrm{C}$ used in the studies, and he included in the meta-analysis a study in which only $0.025-0.050 \mathrm{~g} / \mathrm{d}$ of the vitamin was used. The studies known to Chalmers that had used $\geq 1 \mathrm{~g} / \mathrm{d}$ of vitamin $\mathrm{C}$ were recently reanalyzed and the common cold episodes were calculated to be $0.93 \pm 0.22$ (SE) days shorter in the vitamin groups. ${ }^{16}$ An estimate more than eight times Chalmers' estimate was thus obtained by employing correct values and considering only studies that used doses as high as Pauling ${ }^{1,2}$ had proposed. The problems of Chalmers' review have been discussed in more detail elsewhere. ${ }^{16}$

\section{Dykes and Meier's 1975 Review}

In 1975, the Journal of the American Medical Association published a review of vitamin $\mathrm{C}$ and the common cold by Michael Dykes and Paul Meier, ${ }^{24}$ which contained several shortcomings worthy of note. For instance, while Dykes and Meier discussed the technical aspects of certain studies, in most cases they did not present the original results, thereby hampering the reader in drawing his or her own conclusions about the published results.

The primary results of Anderson et al.'s ${ }^{5} 1972$ study were presented by Dykes and Meier, but certain important findings were neglected. For example, on biological grounds one would expect the benefit of supplementation to be greater for subjects with a low dietary vitamin $\mathrm{C}$ intake. Indeed, in Anderson's study vitamin C ( $1 \mathrm{~g} / \mathrm{d}$ regularly, $3 \mathrm{~g} / \mathrm{d}$ extra during a cold) decreased the total number of "days confined to house" per person by $48 \%$ in subjects with a low intake of fruit juices $(<0.12 \mathrm{~L} / \mathrm{d})$. The decrease was only $22 \%$ in those with a higher intake of fruit juices. ${ }^{5}$ Similar results were obtained in Anderson et al.'s ${ }^{26} 1975$ study, indicating that the subgroup difference was not just statistical fluctuation.

Dykes and Meier ${ }^{24}$ commented on Coulehan's 1974 study ${ }^{9}$ of 
schoolchildren: "Because the data required for an appropriate analysis are not presented, the statistical significance of the differences reported cannot be considered to have been established." However, Coulehan et al. ${ }^{9}$ explicitly reported that $32 \%$ (61 of 190) of lower grade children administered vitamin $C$ were "never ill on active surveillance," while only 16\% (30 of 192) of those administered placebo were never ill. It is highly unlikely that such a difference in favor of vitamin $C$ would be caused purely by chance $(P=0.0002 ; 2$-tailed Fisher's exact test). The data for children in the higher grades was also presented: $63 \%(82 / 131)$ of those administered vitamin $\mathrm{C}$ were "never ill on active surveillance," but only $49 \%(63 / 128)$ of those administered placebo were never ill ( $P=0.041$; 2-tailed Fisher's exact test). Thus, important elements of Coulehan's ${ }^{9}$ results were explicitly published and can be statistically re-analyzed, in contrast to Dykes and Meier's claims. Furthermore, Coulehan et al. ${ }^{9}$ found that the duration of colds was $12 \%$ and $29 \%$ shorter in children administered 1 and $2 \mathrm{~g} / \mathrm{d}$ of vitamin $\mathrm{C}$ respectively suggesting dose dependency up to $2 \mathrm{~g} / \mathrm{d}$, but these data were not given by Dykes and Meier.

Karlowski et al. ${ }^{10}$ carried out a vitamin C-common cold study at the National Institutes of Health, which was published in the same issue of the Journal of the American Medical Association as the Dykes and Meier review. Karlowski used placebo capsules containing lactose, which can easily be distinguished from ascorbic acid by taste. The authors suggested that the apparent benefit due to vitamin $\mathrm{C}$ was caused by the placebo effect, as some of the subjects admitted having tasted their capsules. This interpretation was uncritically reiterated by Dykes and Meier. ${ }^{24}$ The "'placebo effect" explanation, however, is simply inconsistent with Karlowski's data. ${ }^{11}$ Compared to the placebo group, $3 \mathrm{~g} / \mathrm{d}$ of vitamin $C$ decreased the duration of colds by $6-9 \%$, whereas $6 \mathrm{~g} / \mathrm{d}$ decreased it by $17 \%$, suggesting dose dependency up to 6 $\mathrm{g} / \mathrm{d} .{ }^{10,11}$ Dykes and Meier did not reveal the results of Karlowski's study in their review, apparently due to their faith in the "placebo effect" explanation.

In the case of Ritzel's study of schoolchildren in a ski resort, Dykes and Meier did not mention that there was a $29 \%$ decrease in the mean duration of episodes, a $45 \%$ decrease in the incidence of colds, and a $61 \%$ decrease in the total number of days of illness per person in the group administered $1 \mathrm{~g} / \mathrm{d}$ of vitamin $C^{1,2,27-29}$ Dykes and Meier ${ }^{24}$ merely commented that the difference in cold incidence in the two groups was only marginally significant $(P$ $=0.04 ; 2$-tailed), which appears to be intentional camouflaging of the actual results.

Dykes and Meier also discussed a few more studies of lesser importance, but excluded some studies using large vitamin $C$ doses $(\geq 1 \mathrm{~g} / \mathrm{d})$, although these had been published prior to their review. ${ }^{29,30}$

\section{Truswell's 1986 Minireview}

In 1986, the New England Journal of Medicine published a brief analysis of the vitamin C-common cold studies as a letter by A. Steward Truswell. ${ }^{25}$ The main text was half a column long, and in this respect it was a highly superficial review. However, the forum, a journal with great prestige and a very wide circulation, makes the statements in this minireview influential and worthy of brief comments.

Truswell did not present any figures or $P$ values from the original reports, offering only subjective conclusions about the studies. He made no efforts to rationalize the great variations in the published results. For example, on pharmacologic grounds it would seem obvious that the dose is an important variable affecting the results, yet Truswell made no distinction between studies using $6 \mathrm{~g} / \mathrm{d}^{10}$ and $0.05 \mathrm{~g} / \mathrm{d}^{31}$ of vitamin $C$.
Truswell, ${ }^{25}$ referring to certain common cold studies, stated that, "there was no reduction in duration or severity with ascorbic acid as compared with placebo." ${ }^{15,31-37}$ Actually, Coulehan et al., ${ }^{32}$ Clegg and Macdonald, ${ }^{33}$ and Elwood et al. ${ }^{34}$ found a 5-6\% shorter duration of cold episodes in the vitamin $\mathrm{C}$ group $(1 \mathrm{~g} / \mathrm{d})$. Miller et al. $^{35}$ found an $8 \%$ decrease in the "average duration of episodes" and a $12 \%$ decrease in "days in bed" among twins administered $0.5-1.0 \mathrm{~g} / \mathrm{d}$ of the vitamin. A small but reproducible benefit suggests that there may be a real physiologic effect. The effect could be greater in some other groups of subjects and with larger doses, so that it is inaccurate to describe these four independent studies as if no reduction were observed at all. Cowan et al. ${ }^{36}$ reported $31 \%$ less days lost from school per person in subjects given $0.1-0.2 \mathrm{~g} / \mathrm{d}$ of vitamin C. ${ }^{1,2}$ Glazebrook and Thomson $^{37}$ found no effect on the duration of colds, but a $40 \%$ decrease in the average stay in the hospital due to tonsillitis in children administered $0.05-0.3 \mathrm{~g} / \mathrm{d}$ of vitamin $\mathrm{C}$. ${ }^{1}$

At the end of his minireview, Truswell ${ }^{25}$ further claims that "in another five combined trials there appeared to be slight amelioration of symptoms, which was not statistically significant." $10,12,38-40$ in fact, all of the six studies reported in the five papers cited had found a statistically significant benefit in one of the outcome parameters (Table II). Thus, Truswell's statement is gravely misleading, even though the five reports did contain some other outcomes in which the benefit was not significant statistically.

\section{DISCUSSION}

\section{Conceptual Problems in the Interpretation of Common Cold Studies}

In 1971 Pauling carried out a meta-analysis of four placebocontrolled vitamin $\mathrm{C}$-common cold studies, calculating that there was very low probability $\left(P<0.00003^{2}\right)$ that all the reported benefits were purely due to chance. There were technical deficiencies in the studies on which Pauling based his hypothesis and consequently it was possible that the apparent effects were due to biases in the studies. Nevertheless, trials carried out since the early 1970s have consistently shown that vitamin C supplementation alleviates the symptoms of the common cold, indicating that the vitamin does indeed have physiologic effects (Tables I and II ${ }^{3,441}$ ). With this experimental background it seems surprising that a widely held opinion that vitamin $\mathrm{C}$ has no proven effects on the common cold persists. ${ }^{2025}$

Usually the evaluation of the potential effectiveness of a therapeutic method depends greatly on the possibility of biologically rationalizing the method. Goodwin and Goodwin ${ }^{42,43}$ reviewed several cases in which an effective method of treatment was erroneously rejected due to a lack of understanding of the physiologic mechanism of the effect. Thus, the question in evaluating a new method of therapy is not just whether a moderate effect is reproducible in controlled trials.

It seems quite clear that the great quantitative variation in the results is one of the factors hampering the conclusion that vitamin $\mathrm{C}$ has real effects on the severity of colds. However, it has been previously proposed that there also are conceptually much deeper problems in the interpretation of the results, at the paradigm level, to use Thomas Kuhn's terminology. ${ }^{446}$ Traditionally it has been assumed that vitamin $\mathrm{C}$ only prevents scurvy and apparently this notion has created strong prejudices against all other physiologic effects produced by this vitamin. ${ }^{11,44,45}$

The view that vitamin $C$ has some effects on the immune system and on the susceptibility to infections is an old one, long predating Pauling's analyses. ${ }^{47-49}$ Also, it has been known since the 1940 s that the concentration of vitamin C in leuko- 
TABLE II.

FIVE TRIALS IN WHICH THE AMELIORATION OF COMMON COLD SYMPTOMS BY VITAMIN C WAS NOT STATISTICALLY SIGNIFICANT ACCORDING TO TRUSWELL ${ }^{25}$

\begin{tabular}{|c|c|c|c|c|c|}
\hline Study (Ref.) & $\begin{array}{l}\text { No. of } \\
\text { subjects }\end{array}$ & $\begin{array}{l}\text { Vitamin C } \\
\text { dose }(g / d)\end{array}$ & $\begin{array}{c}\text { Effect of vitamin C } \\
(\%)\end{array}$ & $\mathrm{P}$ (two-tailed) & Outcome \\
\hline Karlowski et al. $1975(10,11)$ & 103 & 6 & -17 & 0.047 & Duration of symptoms \\
\hline Pitt \& Costrini 1979 (12) & 674 & 2 & -5 & 0.023 & Severity of symptoms \\
\hline Ludvigsson et al. $1977(38)^{*}$ & 158 & 1 & -39 & 0.003 & Duration of symptoms \\
\hline Ludvigsson et al. $1977(38)^{*}$ & 615 & 1 & -14 & 0.016 & Absence from school \\
\hline Carr et al. 1981 (39) & 190 & 1 & -19 & $<0.05$ & Duration of symptoms \\
\hline Wilson et al. $1973(40) \dagger$ & 128 & 0.2 & -45 & 0.035 & Intensity of symptoms \\
\hline
\end{tabular}

In all listed studies placebo was administered to the control subjects, and the effect refers to the difference between the vitamin $\mathrm{C}$ and placebo groups. The exact $P$ values were calculated when appropriate data were available.

* Ludvigsson reported the results of two separate studies in the same paper.

$\dagger$ "Whole colds" among girls administered $0.2 \mathrm{~g} / \mathrm{d}$ of vitamin C; for details, see ref. 40.

cytes is tens of times higher than in blood plasma, ${ }^{50,51}$ and it was known even earlier that leukocytes participate in defense against infectious agents. It does not seem reasonable to assume that leukocytes would serve only as a storage compartment, and the high concentration of vitamin $\mathrm{C}$ thus suggests that it has functional roles in these immune system cells. Had the reviewers been more familiar with the previous work on vitamin $\mathrm{C}$ and the immune system, they might presumably have been more rigorous in their analyses of the common cold trials. ${ }^{23-25}$

The magnitude of the effect considered clinically significant may also be an issue confounding the analysis of the common cold studies. Many antibiotics have truly dramatic effects on certain bacterial infections and vitamin $\mathrm{C}$ has such an effect on scurvy. Possibly the reviewers had such truly dramatic effects in mind when considering whether vitamin $\mathrm{C}$ has clinically meaningful effects on colds. For example, Dykes and Meier ${ }^{24}$ said of Anderson's 1972 study that "the estimated effect is considerably less than that predicted by Pauling for the dose level." Anderson had reported a 30\% decrease $(P<0.001)$ in the total number of days confined to house per subject. ${ }^{5}$ Many people might consider that with an inexpensive nutrient that costs pennies per gram and that is safe in large doses ${ }^{41,52,53}$ even such moderate benefits are worthy of exploitation irrespective of how they compare to Pauling's predictions.

A further conceptual problem may be the high doses of vitamin $\mathrm{C}$ used in the studies. The doses that have consistently shown benefits $(1-6 \mathrm{~g} / \mathrm{d})$ are some hundreds of times greater than the doses which prevent scurvy $\left(0.01 \mathrm{~g} / \mathrm{d}^{20,51}\right)$. Consequently, the doses used in the common cold studies may appear "pharmacologic" rather than "physiologic." However, it has been estimated that the diet of our ancestors contained $0.4-2.0 \mathrm{~g} / \mathrm{d}$ of vitamin $\mathrm{C}^{41,54,55}$ and the gorilla, a close biological relative of ours, obtains some grams of vitamin $\mathrm{C}$ per day in its diet. ${ }^{49}$ Evidently there has been an evolutionary trend in our ancestors to manage with smaller vitamin $\mathrm{C}$ intakes, especially in the Northern regions where fruits were not available. No strong conclusions can therefore be drawn from the evolutionary data as regards the optimum dose for modern human beings. Nevertheless, the evolutionary data indicate that gram doses of the vitamin are not strictly unfamiliar to human physiology.

Finally, one problem in the analysis of the vitamin C supplementation studies may be the social implications. For example, if vitamin supplements are shown to be beneficial for certain pur- poses, there may be a concern that some people would prefer to eat a poor quality diet and supplement it with vitamins rather than eat a higher quality diet containing lots of fruits and vegetables. It is also possible that any modest effects may be greatly exaggerated by commercial entrepreneurs. Nevertheless, such social concerns should not bias investigation of the actual scientific questions, although they should make a reviewer cautious in the exact formulation of his or her conclusions.

Pauling complained that many of his critics had not read either his texts or the original reports carefully, giving several examples to support his assertion. ${ }^{41}$ The diverse and numerous shortcomings in the three major reviews discussed here support Pauling's allegations. In fact, motivated by the numerous shortcomings in the Dykes and Meier review, Pauling submitted an analysis of the vitamin C-common cold studies to the Journal of the American Medical Association. It was rejected even though Pauling twice made revisions to meet the suggestions of the referees ${ }^{30,49}$ and it was finally published elsewhere. ${ }^{29,30}$ As a further example of careless reading or reporting by Pauling's critics, Chalmers claimed that "Pauling averaged $P$ values from the different studies." 23 However, in his statistical analysis Pauling ${ }^{2}$ explicitly used the well-established Fisher procedure of combining independent $P$ values, ${ }^{17-19}$ which cannot be described as naive averaging of the $P$ values.

\section{Open Questions}

Looking at the studies published to date, it seems clear that Pauling was too optimistic as regards the quantitative benefits of vitamin $\mathrm{C}$ supplementation, although he was correct in his general conclusion that the physiologic effects of vitamin $\mathrm{C}$ are not limited to the prevention of scurvy. Pauling ${ }^{1,2}$ suggested that large doses of the vitamin would substantially decrease the incidence of colds. It is possible that vitamin $\mathrm{C}$ supplementation decreases the common cold incidence in certain restricted groups of people, ${ }^{56,57}$ but there seems to be no worthwhile effect on cold incidence in the general population of Western countries. ${ }^{3,456}$ Pauling's other conclusion, that vitamin $\mathrm{C}$ ameliorates the symptoms of the common cold, has been corroborated in subsequent work, but the benefit has been smaller than he thought. ${ }^{1-4}$

Although placebo-controlled trials have shown that vitamin C has physiologic effects on the common cold, there are scores of open questions awaiting answers. For example, in the case of treating the common cold, it may be asked what is the best method 
of supplementation, what are the optimum doses, what is the maximum treatment effect, and how does the benefit vary among different groups of people? It also seems important to understand the biochemical mechanisms of the effect as this could eventually help in the identification of groups of people who would benefit most. Furthermore, it may be asked whether vitamin $\mathrm{C}$ supplementation has moderate effects on certain other diseases, as has been suggested in a few recent reviews. ${ }^{41,53,58-63}$

Such questions are important, yet they are not often asked.
For example, they have been disregarded in the recommended dietary allowances monograph on nutritional recommendations, ${ }^{20}$ which is concerned only with the prevention of overt scurvy. ${ }^{41,44,45,62-69}$ It is noteworthy and quite surpriseing that in this influential monograph, Chalmers' review ${ }^{23}$ and Dykes and Meier's review ${ }^{24}$ are used as the basis for claiming that vitamin $\mathrm{C}$ has no proven effects on the common cold, ${ }^{20}$ although some of the notable shortcomings of both reviews should have been apparent to anyone familiar with the original publications.

\section{REFERENCES}

1. Pauling L. Vitamin $C$ and the common cold (revised ed.: Vitamin $C$, the common cold, and the flu, 1976). San Francisco: Freeman, 1970

2. Pauling L. The significance of the evidence about ascorbic acid and the common cold. Proc Natl Acad Sci USA 1971;68:2678

3. Hemilä H. Vitamin C and the common cold. Br J Nutr 1992;67:3

4. Hemilä $H$. Does vitamin $C$ alleviate the symptoms of the common cold? A review of current evidence. Scand J Infect Dis 1994;26:1

5. Anderson TW, Reid DB, Beaton GH. Vitamin C and the common cold: a double-blind trial. Can Med Assoc J 1972;107:503

6. Anderson TW, Reid DB, Beaton GH. Vitamin C and the common cold (Correction). Can Med Assoc J 1973;108:133

7. Elliott B. Ascorbic acid: efficacy in the prevention of symptoms of respiratory infection on a Polaris submarine. Int Res Commun Syst/Med Sci 1973;1(3):12

8. Schwartz AR, Togo Y, Hornick RB, Tominaga S, Gleckman RA. Evaluation of the efficacy of ascorbic acid in prophylaxis of induced rhinovirus 44 infection in man. J Infect Dis 1973;128:500

9. Coulehan JL, Reisinger KS, Rogers KD, Bradley DW. Vitamin C prophylaxis in a boarding school. N Engl J Med 1974; 290:6

10. Karlowski TR, Chalmers TC, Frenkel LD, Kapikian AZ, Lewis TL, Lynch JM. Ascorbic acid for the common cold. A prophylactic and therapeutic trial. JAMA 1975;231:1038

11. Hemilä H. Vitamin $C$, the placebo effect, and the common cold. A case study on the role of preconceptions in the analysis of results. J Clin Epidemiol 1996;49:1079 and 1087

12. Pitt HA, Costrini AM. Vitamin C prophylaxis in marine recruits. JAMA 1979; $241: 908$

13. Bancalari A, Seguel C, Neira F, Ruiz I, Calvo C. Prophylactic value of vitamin $C$ in acute respiratory infections of schoolchildren (in Spanish). Rev Med Chile 1984;112:871

14. Mink KA, Dick EC, Jennings LC, Inhorn SL. Amelioration of rhinovirus colds by vitamin $\mathrm{C}$ supplementation. Med Virology 1988;7:356

15. Anderson TW, Suranyi G, Beaton GH. The effect on winter illness of large doses of vitamin C. Can Med Assoc J 1974;111:31

16. Hemilä H, Herman ZS. Vitamin $C$ and the common cold: a retrospective analysis of Chalmers' review. J Am Coll Nutr 1995;14:116

17. Fisher RA. Statistical methods for research workers, 7th ed. London: Oliver and Boyd, 1938

18. Rosenthal R. Combining results of independent studies. Psychol Bull 1978; 85:185

19. Wolf FM. Meta-analysis. Quantitative methods for research synthesis. London: Sage Publications, 1986

20. National Research Council. Recommended dietary allowances. 10th ed. Washington DC: National Academy Press, 1989

21. Gwaltney JM. The common cold. In: Mandell GL, Bennett JE, Dolin R, eds. Principles and practice of infectious diseases. 4th ed. New York: Churchill Livingstone, 1995;561

22. Sperber SJ, Hayden FG. Chemotherapy of rhinovirus colds. Antimicrob Agents Chemother 1988;32:409

23. Chalmers TC. Effects of ascorbic acid on the common cold. An evaluation of the evidence. Am J Med 1975;58:532

24. Dykes MHM, Meier P. Ascorbic acid and the common cold. Evaluation of its efficacy and toxicity. JAMA 1975;231:1073

25. Truswell AS. Ascorbic acid. N Engl J Med 1986;315:709

26. Anderson TW, Beaton GH, Corey PN, Spero L. Winter illness and vitamin C: the effect of relatively low doses. Can Med Assoc J 1975;112:823
27. Ritzel G. Critical analysis of the role of vitamin $\mathrm{C}$ in the treatment of the common cold (in German). Helv Med Acta 1961;28:63

28. Ritzel G. Ascorbic acid and the common cold. JAMA 1976; 235:1108

29. Pauling L. Ascorbic acid and the common cold: evaluation of its efficacy and toxicity. Part I. Medical Tribune 1976;17(12):18

30. Pauling L. Ascorbic acid and the common cold. Part II. Medical Tribune 1976;17(13):37

31. Dahlberg G, Engel A, Rydin H. The value of ascorbic acid as prophylactic against common colds. Acta Med Scand 1944; 119:540

32. Coulehan JL, Eberhard S, Kapner L, et al. Vitamin C and acute illness in Navajo schoolchildren. N Engl J Med 1976;295:973

33. Clegg KM, Macdonald JM. L-ascorbic acid and D-isoascorbic acid in a common cold survey. Am J Clin Nutr 1975;28:973

34. Elwood PC, Lee HP, Leger AS, Baird IM, Howard AN. A randomized controlled trial of vitamin $\mathrm{C}$ in the prevention and amelioration of the common cold. Br J Prev Soc Med 1976; 30:193

35. Miller JZ, Nance WE, Norton JA, et al. Therapeutic effect of vitamin C. A co-twin control study. JAMA 1977;237:248

36. Cowan DW, Diehl HS, Baker AB. Vitamins for the prevention of colds. JAMA 1942;120:1268

37. Glazebrook AJ, Thomson $\mathrm{S}$. The administration of vitamin $\mathrm{C}$ in a large institution and its effect on general health and resistance to infection. J Hygiene 1942;42:1

38. Ludvigsson J, Hansson LO, Tibbling G. Vitamin C as a preventive medicine against common colds in children. Scand J Infect Dis 1977;9:91

39. Carr AB, Einstein R, Lai LYC, Martin NG, Starmer GA. Vitamin $\mathrm{C}$ and the common cold. Using identical twins as controls. Med J Aust 1981;2:411

40. Wilson CWM, Loh HS, Foster EG. The beneficial effect of vitamin $\mathrm{C}$ on the common cold. Eur J Clin Pharmacol 1973;6:26

41. Pauling L. How to live longer and feel better. New York: Freeman, 1986

42. Goodwin JS, Goodwin JM. Failure to recognize efficacious treatments: a history of salicylate therapy in rheumatoid arthritis. Persp Biol Med 1981;31:78

43. Goodwin JS, Goodwin JM. The tomato effect. Rejection of highly efficacious therapies. JAMA 1984;251:2387

44. Hemilä H. Nutritional need versus optimal intake. Med Hypotheses 1984;14:135

45. Hemilä H. A re-evaluation of nutritional goals—not just deficiency counts. Med Hypotheses 1986;20:17

46. Kuhn TS. The structure of scientific revolutions. 2nd ed. Chicago: University of Chicago Press, 1970

47. Hess AF. Diet, nutrition and infection. N Engl J Med 1932;207:637

48. Perla D, Marmorston J. Role of vitamin C in resistance. Parts I and II. Arch Pathol 1937;23:543 and 683

49. Bourne GH. Vitamin C and immunity. Br J Nutr 1949;2:341

50. Crandon JH, Lund CC, Dill DB. Experimental human scurvy. N Engl J Med 1940;223:353

51. Vitamin $C$ requirement of human adults. Experimental study of vitamin C deprivation in man. Lancet 1948;254:853

52. Rivers JM. Safety of high-level vitamin C ingestion. Ann NY Acad Sci 1987;498:445

53. Bendich A, Langseth L. The health effects of vitamin C supplementation: a review. J Am Coll Nutr 1995;14:124

54. Pauling L. Evolution and the need for ascorbic acid. Proc Natl Acad Sci USA 1970;67:1643 
55. Eaton SB, Konner M. Paleolithic nutrition. A consideration of its nature and current implications. N Engl J Med 1985;312:283

56. Hemilä $\mathrm{H}$. Vitamin $\mathrm{C}$ intake and susceptibility to the common cold. Br J Nutr 1997;77:59

57. Hemilä H. Vitamin C and common cold incidence: a review of studies with subjects under heavy physical stress. Int J Sports Med 1996; $17: 379$

58. Bielory L, Gandhi R. Asthma and vitamin C. Ann Allergy 1994;73:89

59. Block G. Vitamin $\mathrm{C}$ and cancer prevention: the epidemiologic evidence. Am J Clin Nutr 1991;53:270S

60. Simon JA. Vitamin C and cardiovascular disease: a review. J Am Coll Nutr 1992;11:107

61. Hemilä H. Vitamin C and infectious diseases. In: Packer L, Fuchs J, eds. Vitamin $C$ in health and disease. New York: Marcel Dekker, 1997 (in press)

62. Ginter E. Ascorbic acid in cholesterol metabolism and in detoxifi- cation of xenobiotic substances: problem of optimum vitamin C intake. Nutrition 1989;5:369

63. Hemilä H. Vitamin C and plasma cholesterol. Crit Rev Food Sci Nutr 1992;32:33

64. Pauling L. Are recommended daily allowances for vitamin $\mathrm{C}$ adequate? Proc Natl Acad Sci USA 1974;71:4442

65. Hughes RE. Recommended daily amounts and biochemical roles. In: Counsell JN, Hornig DH, eds. Vitamin C. London: Applied Science Publishers, 1981:75

66. Levine M, Morita K. Ascorbic acid in endocrine systems. Vitam Horm 1985;42:1

67. Levine M. New concepts in the biology and biochemistry of ascorbic acid. N Engl J Med 1986;314:892

68. Hemilä $H$. Is there a biochemical basis for 'nutrient need'? Trends Food Sci Technol 1991;2:73

69. Reynolds RD. Vitamin supplements: current controversies. J Am Coll Nutr 1994;13:118 